\title{
Monitoring eye movements under conditions of high and low intralist response (meaningful) similarity'
}

P. D. MeCORMACK, T. E. HANNAH, W. J. BRADLEY AND T. E. MOORE

CARLETON UNIVERSITY, OTTAWA, CANADA

Eye movements were monitored as Ss learned lists of high (Group H) and low (Group L) intraresponse similarity. The learning for Group L was superior, with the fixation functions of both groups resembling those of previous studies. Group $H$ appeared to move more rapidly from Stage 1 to Stage 2 even though their consolidation of the responses seemed to be inc omplete.

Underwood, Runquist, \& Schulz (1959) conducted a study employing a list made up of 10 stimulus-response (S-R) pairs where the stimuli were nonsense syllables of low intralist similarity while the responses were two-syllable adjectives more or less synonymous in meaning in one list and unrelated in meaning in another. Two groups of Ss were given a sertes of response familiarization trials prior to the learning of either the high or low similarity list, with tests for response recall being administered after each familiarization trial. Two more groups learned either the high or low similarity lists without any prior famlliarization. Twelve additional groups of Ss were given pairedassociate (PA) learning which, for the administration of response recall trials, was interrupted after one of each of six different exposures to the list. Among other findings, Ss showed better recall of responses with the high similarity than with the low similarity materials during the response recall trials which were given either during familiarization sessions or during the learning of the PA lists. On the other hand, the lists themselves were learned more rapidly under the low similarity condition. It thus appears that conditions of high intralist response similarity facilltate response learning (Stage 1) but retard hook-up (Stage 2).

In a recent series of studies (e.g., McCormack \& Haltrecht, 1966) eye movements were monitored while Ss learned PA lists by the recall method. In all cases, CVCs were employed as both stimulus and response members under conditions of low intralist stimulus and response similarity. During early learning trials, Ss viewed the response more than the stimulus while looking first to the stimulus and then to the response. As learning progressed, the stimulus came to be viewed more than the response, with Ss exhibiting a pattern of looking first to the stimulus, then to the response, and then back to the stimulus. These findings were interpreted as being consistent with the two-stage conceptualization of verbal learning of Underwood, Runquist, and Schulz.

In the present experiment, Ss' eye movements were photographed as they were given 12 trials on each of the two lists of the Underwood, Runquist, and Schulz study. It was predicted that the fixation functions of the earlier investigations would be revealed even though highly meaningful words were employed as responses for the first time. It was also predicted that the stimulus and response fixation functions would diverge more rapidly for those Ss learning the list of similar responses since presumably these Ss would proceed through Stage 1 more rapidly than those exposed to the responses which were unrelated in meaning. Subjects and Apparatus

Ss were 12 male and 16 female students of introductory psychology. The two 10-pair lists were those of Underwood, Runquist, \& Schulz (1959) and were projected by means of a timer controlled Carousel unit to a white surfaced screen $1.4 \mathrm{~m}$ from $\mathrm{S}$ and $2.4 \mathrm{~m}$ from the projector. Eye movements were recorded by means of a head-mounted eye-marker camera (Mackworth \& Thomas, 1962), consisting of a $2 \times 8 \mathrm{~mm}$ motion picture unit filming at a speed of 16 frames per sec and a periscope that reflects a spot of light from the cornea to the film. The film, when developed, shows the PA slides and, superimposed upon each, a bright circular spot indicating the approximate position of actual fixation. The data were analyzed frame by frame by examining the $S-R$ slides through a film viewer. Procedure

Ss were assigned at random to the two groups, Group $H$ (high intralist response similarity) and Group L (low intralist response similarity), with the restriction that there be six males and eight females in each. On any given trial, the $10 \mathrm{~S}-\mathrm{R}$ pairs were presented consecutively. During this study phase, $S$ was instructed to examine the pairs in an attempt to learn them. Following a $2 \mathrm{sec}$ interval, the 10 stimuli were presented, with $\mathrm{S}$ attempting to recall the appropriate responses during this test phase. Slides changed every $2 \mathrm{sec}$, the intertrial interval was $2 \mathrm{sec}$, and a 1 min rest was given at the end of every three trials to enable fllm changeover. The lists were presented in each of three different random orders in an attempt to minimize serial learning, and the session was terminated at the completion of 12 trials. The eye movement data were analyzed for the first six trials only.

Resulis and Discussion

As in the Underwood, Runquist, \& Schulz (1959) study, Ss of Group L learned their list at a faster rate than those of Group $\mathrm{H}$. The mean number of correct responses on Trial 12 was 8.93 for Group $L$ and 6.43 for Group $H$, the latter value being approximately equal to that for Group L Ss on Trial 6. The overall difference between the groups was evaluated by means of a Mann-Whitney $U$ test (the learning data exhibited het- 
erogeneous variance in early and late trials) and was found to be statistically dependable $(p<.025)$.

The fixation data are presented in Fig. 1 for Group $L$ and in Fig. 2 for Group $H$. In both, the first six trials are shown along the abscissa while the ordinate represents mean number of frames per syllable pair for those slides where the stimulus and response appeared together. In these figures, $L$ and $H$ refer to the two groups while $\mathbf{S}$ and $\mathbf{R}$ represent stimulus and response fixations, respectively.

An analysis of variance of these data revealed a reliable Conditions ( $\mathrm{S}$ vs $\mathrm{R}$ ) by Trials interaction $(\mathrm{F}=$ 3.75 , $\mathrm{df}=5 / 286, \mathrm{p}<.005$ ) indicating a dependable divergence of the fixation functions over trials. The relatively early crossover between Trials 1 and 2 was not surprising since Stage 1 (response consolidation) would be expected to be brief for both groups where highly meaningful words were employed as responses. Apart from this early crossover, these data are like those of earlier studies where CVCs were employed on both the stimulus and response sides, and are consistent with the two-stage notion.

It is apparent from Figs. 1 and 2 that the fixation functions diverged more rapidly for Ss of Group $H$. Although the triple interaction $F$ ratio did not rellably exceed its expected value of unity. under the null hypothesis, the Groups by Conditions interaction approached significance $(F=2.91, \mathrm{df}=1 / 286, \mathrm{p}<.10)$. This greater disproportionate viewing of the stimulus on the part of Group $H$ was predicted and is consistent with the findings of Underwood, Runquist, \& Schulz (1959), which revealed that these Ss move more rapidly from Stage 1 to Stage 2.

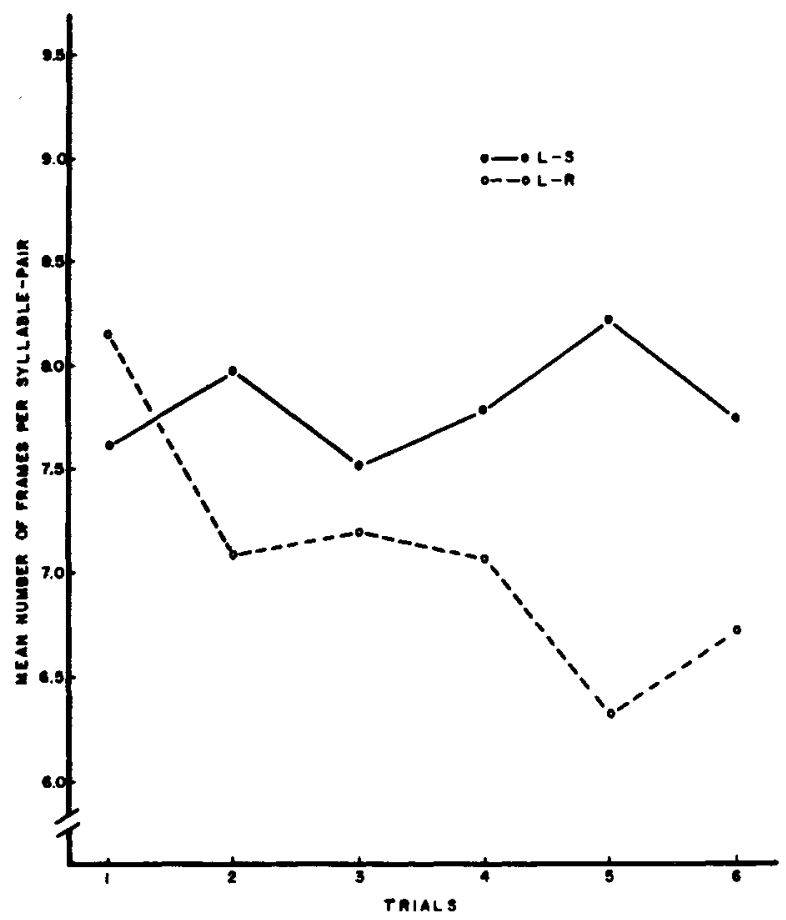

Fig. 1. Mean number of stimulus and response frames per syllable-pair as a function of the first 6 trials for Group $L$.

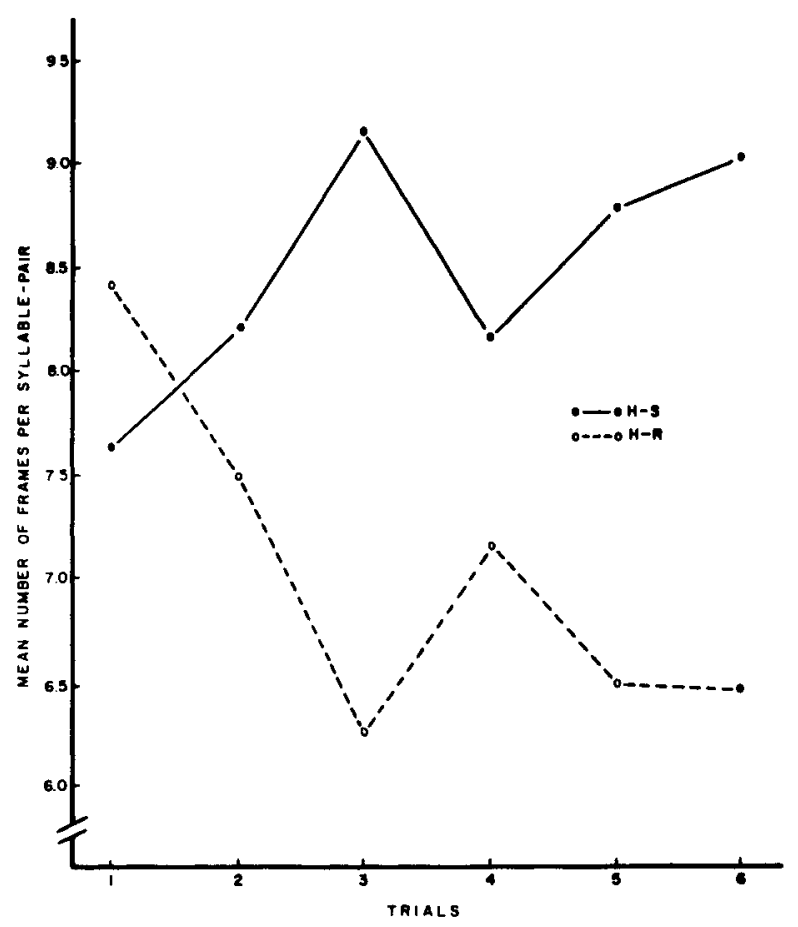

Fig. 2. Mean number of stimulus and response frames per syllable-pair as a function of the first 6 trials for Group $\mathbf{H}$.

In agreement with earlier studies was the increased viewing of the response by 10 of the 14 Ss of Group $H$ from Trials 3 to 4 , where a 1 min rest was introduced to enable $E$ to change film. This phenomenon has been observed whenever the material has been difficult (e.g., Haltrecht \& McCormack, 1966), whether this be due to the nature of the list or to the nature of $S$, or both. There was no evidence in the intrusion data of the present study that Group $\mathrm{H}$ Ss had difficulty in discriminating among the responses. Thus response consolidation appears to be incomplete at the time of the first film change for relatively difficult material.

The eye movement data exhibited the usual transition from $S-R$ to $S-R-S$ viewing over trials $(F=3.43$, df $=5 / 130, \mathrm{p}<.01)$. There was a tendency for Group H Ss to show more eye movements earlier in learning, which is again consistent with the notion that they enter Stage 2 sooner than Ss of Group L.

\section{References}

Haltrecht, E. J., \& McComack, P. D. Monitoring eye movements of slow and fast learners. Psychon. Sci., 1966, 6, 461-462. Mackworth, N. H., \& Thomas, E. L. Head-mounted eye-marker camera. J. Opt. Soc. Amer., 1962, 52, 713-716.

McComack, P. D., \& Haltrecht, E. J. Monitoring eye movements under two conditions of presentation of paired-associate materials. Canad. J. Psychol., 1966, 20, 154-159.

Underwood, B. J., Runquist, W. N., \& Schulz, R. W. Response learning in paired-associate lists as a function of intralist similarity. J. exp. Psychol., 1959, 58, 70-78.

\section{Note}

1. This research was supported by a grant-in-aid from the Associate Committee on Experimental Psychology of the National Research Council of Canada (Grant APA-78). 